\title{
Louis Pasteur, the father of immunology?
}

\author{
Kendall A. Smith* \\ The Division of Immunology, Department of Medicine, Weill Medical College, Cornell University, New York, NY, USA
}

\section{Edited by:}

Donna L. Farber, Columbia University Medical Center, USA

\section{Reviewed by:}

Kai-Michael Toellner, University of Birmingham, UK

Anthony Vella, University of

Connecticut Health Center, USA

\section{*Correspondence:}

Kendall A. Smith, The Division of Immunology, Department of Medicine, Weill Medical College, Cornell University, 407 East 61st Street, New York, NY 10065, USA. e-mail: kasmith@med.cornell.edu
Louis Pasteur is traditionally considered as the progenitor of modern immunology because of his studies in the late nineteenth century that popularized the germ theory of disease, and that introduced the hope that all infectious diseases could be prevented by prophylactic vaccination, as well as also treated by therapeutic vaccination, if applied soon enough after infection. However, Pasteur was working at the dawn of the appreciation of the microbial world, at a time when the notion of such a thing as an immune system did not exist, certainly not as we know it today, more than 130 years later. Accordingly, why was Pasteur such a genius as to discern how the immune system functions to protect us against invasion by the microbial world when no one had even made the distinction between fungi, bacteria, or viruses, and no one had formulated any theories of immunity. A careful reading of Pasteur's presentations to the Academy of Sciences reveals that Pasteur was entirely mistaken as to how immunity occurs, in that he reasoned, as a good microbiologist would, that appropriately attenuated microbes would deplete the host of vital trace nutrients absolutely required for their viability and growth, and not an active response on the part of the host. Even so, he focused attention on immunity, preparing the ground for others who followed. This review chronicles Pasteur's remarkable metamorphosis from organic chemist to microbiologist to immunologist, and from basic science to medicine.
The microscope or the telescope, which of the two has the grander view?

\section{(Hugo, 1862, Les Miserables)}

\section{INTRODUCTION}

As a student of immunology, I learned that Louis Pasteur was really the father of immunology, despite Edward Jenner's pioneering introduction of vaccination to prevent smallpox in 1798 (Smith, 2011). Although successful, Jenner's experiments led to no understanding as to how immunity develops. By comparison, in addition to his many contributions to microbiology, Pasteur introduced the concept that vaccination could be applied to any microbial disease, and he reported methods as to how the virulence of microbes could attenuated so that live microbes could be used to make prophylactic vaccines that could be made in the laboratory and manufactured in unlimited quantities for use worldwide. As if that were not enough, Pasteur also introduced the concept of therapeutic vaccines with his studies of rabies. Thus, he showed that what we now call post-infection prophylaxis could be used to treat individuals who were exposed to a virulent organism, and if applied soon enough after infection, clinical disease and death could be averted. Thus, he offered the hope that infectious microbial diseases could be both prevented and treated via immunology.

Of course, Pasteur was working at the dawn of microbiology, and using careful quantitative methods, he had already shown that microbes such as yeasts caused fermentation of sugar to produce alcohol, and as well, microbes are responsible for putrefaction, or the decay of tissues. Also, over 20 years, he extended his experiments to show that spoilage associated with the dairy, beer, wine, vinegar, and silk industries was explicable by contamination with bacteria. He is credited with the introduction of "pasteurization," a process of heating to a sub-boiling point for a brief time, followed by rapid cooling, to kill most microbes.

Toward the end of his career, Pasteur moved from microbiology to the study of vaccines, a natural extension, to try to prevent infectious diseases in domestic animals. This change in scientific emphasis necessitated him to gain expertise in handling both small and large animals. To help him in this new experimental direction, Pasteur employed a young physician, Emil Roux.

As I too became interested in vaccines later in my career, I began to wonder about Pasteur's pioneering vaccine work, especially the idea that it was important to use live attenuated microbes to generate immunity. Between the 1880 s and the mid twentieth century, no one had reproduced Pasteur's work, attenuating bacteria to make vaccines. One vaccine had been generated using Pasteur's principles, the live attenuated Yellow Fever Virus vaccine, which was created in the 1930s (Theiler and Smith, 1936). However, reading about this work now, I realized that the attenuated Yellow Fever Virus vaccine was made possible by a single random mutation, so that luck had a great deal to do with this vaccine.

At the time of Pasteur's work, the term virus, derived from the Latin, meaning "poison," was used generally to describe any agent that was found to cause an infectious disease. In the latter half of the nineteenth century techniques introduced by Pasteur, Robert Koch, and others to cultivate these "viruses," ultimately led to the discovery and identification of a myriad of bacteria. At the time, due to Pasteur's work, microbes could be discriminated by the use of very fine filters. Those microbes that could be 
removed by filtration were relatively large and could be cultivated outside the body and observed to form colonies observable by the naked eye. These microbes were subsequently classified as belonging to the Kingdom of Bacteria. Other poisons were smaller and passed through the filters into the filtrate. These became know as viruses, and a filterable agent was the working definition of a virus until the 1940s and 1950s, when the electron microscope allowed a magnification of 10 million times, powerful enough to enable their visualization.

With this as a background, I wondered how Pasteur had attenuated the microbes that he used for his live vaccines, especially the attenuation of bacteria. From experiments beginning in the 1950s, it became known that viruses, such as poliovirus, could be attenuated by prolonged passage in tissue culture, but exactly how this worked in many instances remained unknown until recently. Now, we know that prolonged passaging of viruses in tissue culture cells allows for the accumulation of many spontaneous random mutations throughout the genome. However, exactly which of the mutations cause the loss of virulence of a particular organism usually remains obscure, even today. Therefore, how was Pasteur so brilliant that he could have accomplished this feat with bacteria more than 100 years ago? We still cannot attenuate bacteria easily. We now know that bacteria contain $>4000$ genes, while viruses contain $\sim 10-100$ genes. Moreover, bacteria have their own viruses that can introduce virulence encoding genes. Consequently, unless one knows which of the $>4000$ genes are responsible for the virulence of a particular bacterium, it is impossible to attenuate its virulence simply by passaging it many times in vitro. Now, most of our vaccines against bacterial diseases are not live attenuated organisms. Instead, they consist of parts of the microbe, and are called subunit vaccines, and by definition, they are not living. And how could he have attenuated the rabies microbe, which is now known to be a virus and not a bacterium? And why did his therapeutic vaccine for rabies work so well? We would love to create such a vaccine for diseases such as the Acquired Immunodeficiency Syndrome, due to infection by the Human Immunodeficiency virus. Therefore, it is timely to re-examine Pasteur's methods and findings.

\section{THE ANCIENTS AND THE SECRET OF LIFE}

Our view of our world has necessarily depended on our abilities to actually perceive the nature of our surroundings. The ancients, in particular Aristotle, did not have the advantage of peering through a microscope so as to magnify images many-fold. Consequently, the Greeks concluded that the world is made up of those elements that one could perceive with the five senses; fire, earth, water, and air. Furthermore, living things, plants, and animals, were thought to arise spontaneously from inanimate (i.e., lifeless) material. Thus, from a mixture of earth and water, which formed a primordial terrestrial slime, life was thought to form when the sun's heat acted upon it, thereby forming all living things, plants, animals, and even human beings. In the nineteenth century, this was known as "spontaneous generation." Now, we call this abiogenesis, and some of the best minds are fixated on this question, so that it is still at the forefront of the fundamental unknowns confronting mankind.
Aristotle laid the foundations of Western "natural philosophy" (i.e., science) and the concept of spontaneous generation as follows:

Animals and plants come into being in earth and in liquid because there is water in earth, and air in water, and in all air is vital heat, so that in a sense, all things are full of soul (spirit). Therefore, living things form quickly whenever this air and vital heat are enclosed in anything. When they are so enclosed, the corporeal (bodily) liquids being heated, there arises as it were, a frothy bubble.

Thus, Aristotle described both putrefaction, the decay of living things, as well as fermentation, the giving off of gas and heat, associated with the decay of living things. See: http://ebooks.adelaide. edu.au/a/aristotle/generation/.

\section{THE RENAISSANCE AND THE MICROSCOPE}

These thoughts persisted through two millennia, until the late renaissance in the seventeenth century. The beginning of the end of the idea of spontaneous generation can be credited to Robert Hooke, who first described and coined the word "cell" (from Latin, cella, "storeroom or chamber"). In his "Micrographia: or Some Physiological Descriptions of Miniature Bodies Made by Magnifying Glasses" (Hooke, 1665), he published his observations on his $50 \times$ magnification of thin sections of cork, which he described as comprised of pores or "cells." Subsequently, in 1682 Antoni Van Leeuwenhoek described fish blood cells to the English Royal Society as comprised of a globule surrounded by a border, which he could discern by his construction of microscopes that could amplify images $250 \times$.

However, it was not until the early nineteenth century that microscopes were improved to the magnification of our modern microscopes. Thus, $400 \times$, comprised of a $40 \times$ objective (i.e., high-dry) and a $10 \times$ ocular magnification, first allowed Schwann (1837) and Cagniard-latour (1838) to perform ingenious experiments that refuted spontaneous generation as responsible for putrefaction, or the decay of material leading to a fetid odor or miasma.

Schwann reported experiments showing that if an enclosed glass sphere which contains air and a small amount of an infusion (extract) of meat is heated in boiling water so that the liquid and air of the sphere are warmed to $100^{\circ} \mathrm{C}$, then the liquid shows no putrefaction or production of infusoria (single celled organisms), even after many months. He also performed experiments on alcohol fermentation and concluded that "in alcoholic fermentation as in putrefaction, it is not the oxygen of the air which causes fermentation to occur, but a substance in the air which is destroyed by heat" (Schwann, 1837). The dogma at the time held that both putrefaction and fermentation occurred as a result of the oxygen in the air acting upon organic substances, such that it was only a chemical reaction, and not due to the spontaneous generation of life forms from inorganic materials.

Schwann goes on to state:

Microscopic examination of the beer yeast showed the familiar little grains (kornchen) which the ferment forms, but the majority of these were connected in chains. They were partly round, but mostly oval grains of a light yellow color, which 
occasionally occurred singly, but most often in chains of two to eight or more (Schwann, 1837)

A year later, Charles Cagniard de la Tour goes on to say (Cagniard-latour, 1838)

I am acquainted with the principal literature concerning alcoholic fermentations, but I have seen no work in which the microscope was used to study the phenomenon on which it depends. The principal results of the present work are: 1) The beer yeast is a mass of small globules which are able to reproduce, and consequently, are organized, and are not a simple organic or chemical substance, as has been supposed. 2) These bodies appear to belong to the plant kingdom. 3) They seem to cause a decomposition of sugar only when they are alive, and one can conclude that it is very probable that the production of carbon dioxide and the decomposition of sugar and its conversion to alcohol are effects of their growth.

\section{LOUIS PASTEUR AND THE GERM THEORY: PUTREFACTION AND FERMENTATION}

These rudimentary experiments, the observations and the conclusions, are very important, especially because they were largely ignored for 20 years, and only became accepted when Louis Pasteur repeated these same experiments and first announced them to the Academie des Sciences in a series of presentations beginning in 1857 (Pasteur, 1857). To understand Pasteur's stance on the issue, and his contribution, it is necessary to examine him in relationship to his life in science up until this point, and the society in which he was living, that is the Second Empire. Louis Napoleon was freely elected President of the Second Republic after the revolution of 1848, but he then usurped power and declared himself Emperor in 1852. At the time, the pagan notion that life could arise spontaneously from inanimate objects, without the intervention of the Creator, was extremely unpopular in France, and especially so with the Emperor, who depended upon his position as God's chosen. Pasteur was a sincere believer in a Creator-God, and was emblematic of the nineteenth century French bourgeoisie, a fervent patriot, Bonapartist, and political conservative. It is noteworthy that Darwin's "On the Origin of the Species" was translated into French in 1862 , so that Darwin's evolutionary theory and spontaneous generation were both seen as part of a broader threat to the established order.

However, Pasteur's interest in fermentation, and subsequently in spontaneous generation, originated in his first major scientific discovery in chemistry, that of optical isomers of tartrate, the subject of his doctoral thesis of 1848. Subsequently, Pasteur correlated this optical asymmetry, detected with a polarimeter of the polarization of light by molecules in solution, with the asymmetry of their crystals derived from each of the optical isomers. By the late 1850s, Pasteur's thinking had evolved to include the concept that only asymmetric molecules and crystals were derived from living tissues and organisms, while symmetrical molecules, which did not polarize light, were indicative of inanimate, non-living materials. Thus, Pasteur believed that he was on the verge of discovering one of the fundamental principles that distinguishes living from non-living materials, in other words, the secret of life.
Pasteur made the metamorphosis from chemist to microbiologist at the age of 35 because of a decision to focus on amyl alcohol, which he details in the introduction to his 1857 paper on lactic fermentation (Pasteur, 1857).

I established that amyl alcohol, contrary to what had been believed hitherto, was a complex substance formed of two distinct alcohols, one deviating the plane of polarization of light to the left, the other devoid of all (optical) activity.

Pasteur had come to believe that the optical properties of his two amyl alcohols could only be explained on the assumption that asymmetry, and thus life, somehow intervened in their production during the process of fermentation. These preconceived ideas (idees preconsues) essentially drove his scientific metamorphosis. In his pursuit of his point of view, he challenged some of the leading chemists of his day, notably Justus von Liebig of Germany and Jacob Berzelius of Sweden. However, as noted, he was not alone, in that both Latour and Schwann had already shown that alcoholic fermentation depended on the vital activity of Brewer's yeast. However, this view had been challenged, even ridiculed by Liebig and Berzelius, who both insisted that the process was chemical rather than biological. Thus, before Pasteur could examine the effect of fermentation on amyl alcohols, he had to prove to himself, and others, that fermentation only occurred in the presence of living microscopic organisms.

In his 1857 report on lactic fermentation, Pasteur reports the accumulation of material:

Under the microscope it is seen to form tiny globules or small objects which are very short, isolated or in groups of irregular masses. These globules are much smaller than those of beer yeast and move actively by Brownian movement.

Thus, he accumulated observations consistent with his hypothesis that lactic fermentation occurs in the presence of living organisms. In addition, as a chemist Pasteur argued that if lactic fermentation were a straightforward chemical reaction, it should lead to only the reactants and product(s) of the reaction. However, he reproducibly found several substances resulting from lactic fermentation:

Lactic acid is indeed the principal product of the fermentation which has been given its names but it is far from the only product. Butyric acid, alcohol, mannitol and a viscous material are always found accompanying the lactic acid.

Thus, Pasteur the chemist argued that only a living process could elaborate such a complex mixture of molecules.

In his Memoire sur la fermentation alcoölique, Pasteur (1860) tackled the issue of the chemical vs. biological nature of alcoholic fermentation directly. In his introduction, he detailed the previous work on the biological nature of fermentation.

In 1680 Leeuwenhoek studied beer yeast under the microscope and found very small spherical or oval globules, but the chemical nature of this substance was unknown to him. Fabroni identified the yeast with gluten. This was some progress. It gave an indication that yeast might be an organic product. M. Thenard published a memoir in which he said: All natural sugary juices, in the process of spontaneous fermentation, deposit a substance which resembles beer yeast and 
which has the power of fermenting pure sugar. This yeast is animal in nature, since it is nitrogenous and yields ammonia upon distillation... In his observations published in 1835 and 1837, M. Cagniard de la Tour introduced a new idea. Before his time, yeast had been regarded as a vegetable product, produced in situ, which precipitated out in the presence of a fermentable sugar. M. Cagniard de la Tour recognized "that the yeast was a mass of globules which reproduced by budding, and were not merely a simple chemical or organic substance." He concluded that "it is very probable that the production of carbon dioxide and the decomposition of sugar and its conversion into alcohol are effects of the growth of the yeast."

One can see that one problem at this time was that it had not been established exactly what yeast was, i.e., whether it was plant or animal, or in fact whether it was living or not. Now, it is classified to belong to the Fungi Kingdom.

Pasteur goes on to detail Liebig's position, which was that fermentation occurred because of the decomposition of non-living matter in the presence of oxygen.

This opinion immediately found a powerful opponent in M. Liebig. In his eyes, the ferment is an extremely unstable substance which decomposes itself and which causes fermentation as a result of the decomposition which it itself undergoes, during which it communicates this perturbation and dissimilation to the fermentable material. He expresses himself thus: "The experiments which we have revealed demonstrate the existence of a new cause which brings about decomposition and synthesis. This cause is nothing else than the movement which a body in the process of decomposition communicates to other substances in which the elements are held together very weakly... Beer yeast, and in general all animal and vegetable materials undergoing putrefaction, communicate to other substances the state of decomposition in which they find themselves..."

Pasteur then describes several experiments where he establishes that there is no need for any source of nitrogenous decomposing animal or plant material for fermentation to occur. He can show that nitrogen in the form of ammonia can be used, and that all one needs in addition is sugar and a very small amount of yeast.

It can be stated with certainty that the ammonium salt is indispensable for the fermentation. When yeast is seeded into a sugar solution containing yeast ash but no ammonium salt, there is hardly any sign of fermentation. The necessity of sugar as a source of carbon for the yeast globules has been sufficiently proven that it requires no further experiments. Therefore, all that is necessary to bring about the phenomenon of fermentation are these things: sugar, nitrogenous substance, minerals. . . Sugar never undergoes alcoholic fermentation without the presence of living globules of yeast. Reciprocally, globules of yeast are never formed without the presence of sugar or a carbohydrate material or without the fermentation of this material. Any statements which are contrary to this principle have been derived from incomplete or inexact experiments.
Pasteur's most important contribution in this paper is that the yeast can actually increase extensively in weight and produce alcohol even in a liquid that lacks proteinaceous materials of a natural source. He obtained an active alcoholic fermentation in what we would today call a synthetic (or defined) medium, consisting merely of trace elements, ammonium salt and sugar. The problem became considerably clarified by this observation, since it could easily be shown in such a defined medium that the fermentation always proceeded with the growth of the yeast, and the increase in protein in the yeast was accompanied by a decrease in nitrogen of the medium.

Thus, with his detailed chemical measurements, Pasteur essentially destroyed the arguments of the chemists who held that fermentation resulted from the chemical decomposition of dead animal/plant matter (putrefaction).

Given his commitment to the living microbe explanation of both fermentation and putrefaction, it was almost inevitable that Pasteur would be drawn to the controversy surrounding the concept of spontaneous generation, which had prevailed from the time of Aristotle. Central in this debate were the experiments of Felix-Archimede Pouchet. In contrast to the chemist Pasteur, Pouchet was a generation older, and a respected biologist, with a special interest in embryology and reproductive biology. He was best known for his theory of "spontaneous ovulation," which challenged the once widely accepted belief that the formation of eggs in the ovary depended upon fertilization by contact with sperm from the male (not in the least male chauvinistic). In 1859, he published Heterogenie, ou traite de la generation spontanee, in which he presented all of the evidence in favor of spontaneous generation.

However, by comparison to the pagan Greek belief, i.e., that living matter could arise spontaneously from inanimate matter provided the proper ingredients were exposed to heat from the sun, Pouchet attempted to make his interpretation of spontaneous generation palatable to the conservative Christians of the Second Empire. Heterogenesis, he argued, was not the "chance" doctrine of the ancient atomists. Rather, according to his theory, new organisms arose from the effects of a mysterious and unknowable "force plastique" that could be found in all living organisms, but also in dead plant and animal debris. Thus, for Pouchet "only organic molecules" and not inorganic matter, could be acted upon by the mysterious force plastique to spontaneously generate life. It is noteworthy, in this regard, that organic chemistry first arose in first half of the nineteenth century as a discipline distinct from chemistry. Originally, organic molecules, comprised principally of carbon, were thought only to be synthesized by living organisms, via a vital "life force."

Of course, Pasteur had to deal with this issue, in that if anyone was to understand and agree with his conclusions regarding the role of living organisms from the air as the cause of fermentation, he had to demonstrate that ordinary air actually did contain living microbes, and they were the source of the "spontaneous generation" that Pouchet and others had observed. Pouchet had published an influential paper in 1858 that claimed to offer experimental proof of spontaneous generation. This paper described the appearance of microorganisms in infusions of hay that were boiled under mercury, after exposure to artificially produced air or oxygen. Pasteur's response to the Academie des Sciences in a 
series of five presentations were ultimately compiled in a prizewinning essay, Memoire sur les corpuscles organizes qui existent dans l'atmosphere (Pasteur, 1861). In one of the experiments, which he characterized as "unassailable and decisive," he used what became his famous swan-necked flasks to demonstrate that if atmospheric air was excluded from boiled infusions, then no "living microorganisms would appear, even after months of observation. However, if atmospheric dust were then introduced, living microbes would appear within 2-3 days."

Over the next 20 years, Pasteur went on to perform a series of careful microbiological experiments in studies of the maladies suffered by the dairy industry, silk worm industry, wine industry, vinegar industry, and the beer industry, establishing the importance of microbes for everyday endeavors, truly "applied science." During this time, which spanned the Franco-Prussian war of 1870, the end of the Second Empire and the start of the Third Republic, Pasteur became the equivalent of a "rock star," essentially a household word and the epitome of a scientist, as well as a national hero.

\section{THE DAWN OF INFECTIOUS DISEASE: JOSEPH LISTER, ROBERT KOCH, AND PASTEUR}

Also, during the mid nineteenth century, there were a growing number of reports that microbes isolated from wounds and other degenerative tissues might actually be the cause of the destruction of the normal tissues. However, at the time, the popular notion was that these microbes, if anything, were the result and not the cause of the morbid state. The morbidity was still thought to arise spontaneously via chemical reactions, essentially the ideas of Liebig and Berzelius. Any association with living microbes was considered fortuitist. Thus, the connection between microbes and infectious diseases still had not been made. One exception was Joseph Lister, a British surgeon who had read Pasteur's reports to the Academie des Sciences, and consequently sought to reduce the morbidity and mortality in his practice. He had noticed that if the bones from a fracture punctured the skin there was almost always a resultant collection of putrid pus, most often leading to death. Thus, in 1867 he introduced the application of antisepsis through the use of dilute solutions of carbolic acid, not only for the treatment of compound fractures (Lister, 1867a), but in the preparation of the skin prior to his incision on all of his surgeries (Lister, 1867b). The result was a marked reduction in the routine morbidity and mortality associated with surgery.

Despite this advance, another decade elapsed before a young Prussian physician, Robert Koch, described the first proof that microbes could actually cause an infectious disease (Koch, 1876).

In the words of Eli Metchnikoff, often called the father of cellular immunology for his studies on phagocytosis (Metchnikoff, 1939):

A powerful impulse was necessary to change this inchoate idea of organized ferments into a rigorously proven scientific truth. Robert Koch started such an impetus in his paper on anthrax written in 1876 . This young health officer in the little city of Wolstein, a god-forsaken hole in Posen, suddenly came into the limelight of science. His work was indeed a model of true scientific creativeness. Living in a region in which anthrax was endemic, he set about to study it, without the help of laboratory or library, and always thrown back on his own resources. He worked in his own rooms where for lack of gas illumination he was obliged to use a petroleum lamp. By means of plates covered with moist sand he constructed a semblance of an apparatus for growing cultures of bacteria. Nevertheless he achieved results superior to anything yet accomplished. He was the first to succeed in changing the thread-like microscopical corpuscles identified by others into identifiable long filaments (chains of rods) and then into beads consisting of minute grains, the spores. This great discovery of the spore of anthrax removed all doubts regarding the role of bacteria in the causation of anthrax, for it illuminated all points hitherto left unexplained.

Throughout medieval times, anthrax was a disease primarily of livestock, and it still is considered so. In humans, the most common affliction is a skin inflammation, and in the eighteenth and early nineteenth century, cutaneous anthrax was known as wool sorter's disease, because farmers and mill workers would contract it from handling animals and wool that were contaminated by anthrax spores. However, for the livestock industry, anthrax was a serious problem, in that many animals could succumb to a more serious disease manifested by both gastrointestinal and pulmonary symptoms, followed by shock and death. Once animals died and their corpses were allowed to disintegrate in a pasture, it was well known that if a particular pasture was suspect, the reintroduction of fresh animals in the spring often resulted in a reappearance of the disease. Of course, as a result of Koch's experiments, now we know that the ability of the microbe to sporulate enables it to withstand harsh temperatures and conditions that occur during the winter months.

Two years after Koch's publication proving the microbial nature of anthrax, Pasteur presented a Summary to the Sessions of the Academy of Sciences (Pasteur et al., 1878). According to Pasteur:

The only way currently available to science to experimentally prove that a microscopic organism is the cause of both the illness itself and its transmission, is to subject the microbe to serial cultures.

Pasteur goes on to describe his experiments with the anthrax bacillus, never mentioning that Koch had already demonstrated the culture of the anthrax microbe 2 years earlier. In concluding, he states that:

I ask the Academy not to dismiss these curious results before I demonstrate one important theoretical conclusion. We insist on demonstrating at the start of these studies (that are opening a whole new world of knowledge) a proof that the cause of transmissible, contagious and infectious diseases resides essentially and uniquely in the presence of microorganisms.

\section{PASTEUR'S IMMUNITY}

Only 2 years later, Pasteur again presented to the members of the Academy a treatise entitled "Of Infectious Diseases, Especially the Disease of Chicken Cholera" (Pasteur, 1880).

In this presentation, Pasteur first reminded the members that the theory of spontaneous generation was false, as demonstrated 
by his experiments performed more than 20 years previously. $\mathrm{He}$ then set the stage by stating,

Infectious diseases consist of most of the major disasters, such as small pox, scarlet fever, rubella, syphilis, glanders, anthrax, yellow fever, typhus, and bovine plague.

Pasteur then discussed the phenomenon of vaccination as introduced by Edward Jenner almost 100 years before.

The practices of vaccination and variolization have been known in India for the longest time. Even before Jenner demonstrated the efficacy of vaccinia, people of the countryside where he practiced already knew that cowpox protected against small pox. The facts about vaccinia are unique, but the facts about non-recurrence of virulent diseases are more general. The organism never expresses twice the effect of chicken pox, scarlet fever, typhus, plague, small pox, syphilis, and others, as the immunity persists for a long time at least.

Pasteur then introduced the problem of chicken cholera and mentioned that M. Toussaint, a professor at the veterinary school of Toulouse, had been first to culture and isolate the microbe that he thought to be responsible for the cause of the disease in chickens. Pasteur went on to say that he had discovered an improved culture medium for the microbe, and...

We can diminish the microbe's virulence by changing the mode of culturing. This is the crucial point of my subject. I ask the Academy not to criticize, for the time being, the confidence of my proceedings that permit me to determine the microbe's attenuation, in order to save the independence of my studies and to better assure their progress.

This is a crucial aspect of Pasteur's experiments and of his presentations to the public. In France it was common practice to submit a sealed note (called a pli cachete) on an important scientific discovery to the Academy of Sciences to secure or protect one's priority. In contrast, an official patent (brevet d'invention) was necessary to establish one's right to the commercial exploitation of that discovery. Pasteur thus kept it a secret as to exactly how he had attenuated the virulence of the chicken cholera microbe for more than 9 months, until October of 1880.

Eventually Pasteur disclosed that his methods simply involved culturing the microbe exposed to atmospheric oxygen for prolonged culture intervals, i.e., longer than 2-3 months. However, he never explained why oxygen should weaken microbes, especially the aerobic microbes, of which the chicken cholera was one, and anthrax is another. It is likely that he did not want to risk others trying to repeat his methods, both from the standpoint of the fear of their success, as well as their failure.

Pasteur then described using the "live atmosphere-attenuated" cholera vaccine to immunize animals against lethal challenges of the microbe, and stated that

It seems as if the initial microbe inoculations (of the live attenuated vaccine) have depleted a certain element that healing does not reconstitute and that the absence of which hinders the development of this small organism (when re-inoculated a second, third, and fourth time). This explanation will

\section{without doubt, become general and applied to all infectious diseases.}

I would like to point out to the Academy two main consequences to the facts presented: the hope to culture all microbes and to find a vaccine for all infectious diseases that have repeatedly afflicted humanity, and are a major burden on agriculture and breeding of domestic animals.

The importance of Pasteur's theory, i.e., that it was possible to attenuate the virulence of all microbes, simply by passing them in special culture conditions, can only be appreciated by understanding the competition that developed between Pasteur and Toussaint in the summer of 1880 involving different approaches to the creation of a vaccine for anthrax. The story is detailed in a book entitled "The Private Science of Louis Pasteur" by Gerald Geison, who was Professor of History at Princeton University (Geison, 1995).

Pasteur had begun working on a vaccine for anthrax 3 years previously in 1877, soon after Koch's announcement on the isolation of the causative anthrax bacillus. On July 12, 1880, Henri Bouley (a fellow veterinarian and friend of Toussaint) read before the Academy of Sciences a report from Toussaint (who was not a member of the Academy), which described the initial results of his experimental vaccine trials. In contrast to Pasteur's "live atmosphere-attenuated" vaccine, Toussaint generated his vaccine simply by killing the bacilli by heating for $10 \mathrm{~min}$ at $55^{\circ} \mathrm{C}$. Using this vaccine, Toussaint had conducted trials on $8 \mathrm{dogs}$ and 11 sheep. Of the eight dogs, four had been injected with the vaccine and had survived a series of four successive injections of virulent live anthrax. By comparison, all four unvaccinated dogs succumbed to the first injection. A similar result was obtained with the sheep.

In August while vacationing, Pasteur heard the news of Toussaint's vaccine experiments from Bouley. He responded as follows:

My very good colleague,

Since yesterday morning, when I received your letter, the extracts of the journals, and the Summary of the Academy of Sciences-all at the same time -I have been in astonishment and admiration over the discovery of M. Toussaint-in admiration that it exists, in astonishment that it can be. It overturns all the ideas I had on viruses, vaccines, etc. I no longer understand anything. Ten times yesterday, I had the idea of taking the train to Paris. I really cannot believe this surprising fact until I've seen it, seen it with my own eyes, though the observation that establishes the fact makes me want to confirm it to my own satisfaction.

The Academy of medicine has thus received a severe lesson. It will surely have grasped that one does not deal lightly with facts of this order in public, that contemplation is appropriate in the face of such solutions to such problems.

I am too moved to write more fully. I have dreamed about it, both asleep and awake, all through the night.

Best to you and thanks.

L. Pasteur

As Geison (1995) pointed out, Pasteur's expression of surprise and agitation makes sense only in the context of his general theoretical views on infectious diseases and immunity. Because of 
his successes in his studies of the metabolism of living microbes, Pasteur naturally extended his microbiological concepts to immunity. Linking immunity with the biology of microbes, especially the nutritional requirements of different microbes, he suggested that the tissues of the invaded host might contain only trace amounts of substances required for the growth and survival of the microbe, just as some culture media contained only trace amounts of vital nutrients. If so, the invading microbe might soon exhaust the supply of these trace substances, rendering the host an unsuitable medium for the microbe's subsequent cultivation. Thus, the host would not support the growth of a subsequent infection by the microbe, and would be "immune." Also, an attenuated microbe would be one that had been stressed by cultivation, either in vitro or in vivo, in an environment that was limiting in essential nutrients, thereby causing it to lose its virulence.

Thus, central to Pasteur's conception of immunity, was the biological activity of a living, if attenuated, microbe that depleted the host of essential nutrients. It was Toussaint's claim that he had in fact produced a "dead" vaccine against anthrax that moved Pasteur to state that "it overturns all the ideas I had on viruses, vaccines, etc."

As one might imagine, given Pasteur's theory, and his statements already made to the Academy, his lance had been planted. He could not, and would not, graciously admit that he was wrong. The story only goes downhill from this point. In the public critique that Pasteur was soon to issue against Toussaint's work, his central theoretical concern was precisely the question of "live vs. dead" vaccines.

In August, 1880, soon after announcing his heat killing method of vaccine production, Toussaint switched his procedures and had begun to subject the bacilli to the action of carbolic acid, which Joseph Lister used as an antiseptic for the treatment of surgical wounds.

Pasteur did not announce the discovery of his own "live attenuated" anthrax vaccine until February 28, 1881 (Pasteur et al., 1881b). Of significance, Pasteur linked his new vaccine with his earlier chicken cholera vaccine by ascribing attenuation in both cases to the action of atmospheric oxygen, "atmospheric attenuation." However, there was an important difference between the production methods of the two vaccines. Unlike the chicken cholera microbe, the anthrax bacillus formed spores that "resisted the attenuating effects of atmospheric oxygen." It had taken much time and empirical effort to ascertain that a spore-free culture of anthrax could be produced at a temperature of $42-43^{\circ} \mathrm{C}$.

Subsequently, on March 21st, Pasteur reported further successful results testing his vaccine in sheep, which stimulated a challenge by the Agricultural Society of Melun, at Pouilly-le-Fort, which is $40 \mathrm{~km}$ from Paris. Examination of Pasteur's lab notebooks (Geison, 1995) revealed that he had been conducting small trials, testing his vaccines in animals during this time, with less than conclusive results as to the protective efficacy of the live atmospheric attenuated vaccine. However, at the same time Pasteur's lab was testing a vaccine prepared by $\mathrm{M}$. Chamberland who was experimenting with a vaccine prepared by chemical treatment with potassium-bichromate, which is an oxidant commonly used in chemistry labs to clean glassware. In small-scale tests this vaccine was working.
If Pasteur had failed to accept the challenge from the veterinarians, he would certainly have damaged his reputation in his competition with Toussaint. Moreover, there were already rumors that Pasteur was really seeking to profit financially from his "secret remedies" against livestock diseases. Therefore, Pasteur "impulsively" accepted the challenge and on April 28, 1881, he signed a detailed and demanding protocol, which was performed in May.

Of 50 sheep in the trial, half were vaccinated on May 5 th and May 17th, while the other half served as unvaccinated controls. All of the sheep were then challenged with a virulent culture of anthrax bacilli on May 31st. On June 2, 1881, there were more than 200 observers, including government officials, local politicians, veterinarians, farmers, agriculturists, cavalry officers, and newspaper reporters present to view the results of the experiment. All of the vaccinated sheep were alive, while most of the unvaccinated sheep were already dead, with the remaining obviously very ill.

On June 13, 1881, less than 2 weeks after his celebrated success at Pouilly-le-Fort, Pasteur presented his account of the experiment before the Academie des Sciences (Pasteur et al., 1881a):

The Academie ought to realize that we did not draw up such a (experimental) program without having solid support from prior experiments, although none of these had been of the magnitude of the one which was now prepared. Besides, chance favors the prepared mind, and it is in this sense, I think, that one should understand Virgil's inspired phrase: Audentes fortuna juvat (luck comes to the bold).

In this public account of the anthrax vaccine trial, Pasteur gave few details of the preparation of the vaccine (Pasteur et al., 1881a). Rather, he eluded to the methods that he had already reported for his chicken cholera vaccine:

In sum, we now possess some virus-vaccines of anthrax, capable of providing protection against the fatal disease without ever being fatal themselves, living vaccines, cultivatable at will, transportable anywhere without alteration, and, lastly, prepared by a method that one may consider capable of generalization since it served a previous time for a discovery of the chicken cholera vaccine. By virtue of the conditions that I have enumerated here, and to look at things solely from the scientific point of view, the discovery of these anthrax vaccines constitutes a considerable advance over the Jennerian vaccine against smallpox, for the latter has never been obtained experimentally.

Only Pasteur and his collaborators knew of the real nature of the vaccine used for this famous trial. From examination of Pasteur's lab notebooks by Geison, Pasteur did not use the live attenuated vaccine that he had emphasized was so important for his success with chicken cholera (Geison, 1995). Instead, the vaccine of Toussaint prepared by Chamberland by treatment with potassium-bichromate was used:

The anthrax culture employed for the $1^{\text {st }}$ vaccine, this $5^{\text {th }}$ of May...was an anthrax culture attenuated by Chamberland with bichromate and which, no longer being lethal at all, being reinforced by three successive passages in three mice. 
The second dose of vaccine was also prepared by treatment with potassium-bichromate.

The up-shot of this public triumph of Pasteur's vaccine was that he received credit for developing the first successful vaccine against anthrax. Toussaint subsequently published only 2 more scientific papers before he died in 1890 at the age of 43 , after suffering a mental breakdown. It was not until 1998, that the French government officially recognized Toussaint's vaccine as the first effective vaccine against anthrax. In this regard, it is noteworthy that Robert Koch, who became one of Pasteur's chief competitors, always hailed Toussaint as the worthy inventor of vaccination against anthrax, and persistently denigrated Pasteur's contributions to microbiology (Geison, 1995).

With the success of the anthrax vaccine, Pasteur was intent on using his vaccine efforts on a disease important for humans. Just 9 days after his Academie des Sciences address, on June 22, 1881, he spoke at The International Congress of Directors of Agronomic Stations in Versailles. In speaking about the promise of his atmospheric attenuation method, he said that he had extended the method to a previously unknown "microbe of saliva" that he had detected in a child who had died of rabies.

\section{LA RAGE}

Early on in Pasteur's foray into vaccines, he wanted to find an animal disease that also affected man. Rabies provided that opportunity. Later, after he had "successfully" created a rabies vaccine, he insisted in private correspondence that he had undertaken the study of rabies "only with the thought of forcing the attention of physicians on these new doctrines"-that is to say, the still controversial germ theory of disease, and the technique of vaccination through atmosphere-attenuated cultures (Geison, 1995). He also was quite cognizant of the ethical problems associated with using experimental approaches on humans. Rabies provided the perfect disease, in that it was not an endemic or epidemic disease, like smallpox for example (Smith, 2011). In fact, it was relatively rare, at least in humans. Therefore, a prophylactic trial as in the anthrax experiment with 50 sheep was unapproachable, both for practical as well as ethical reasons. However, rabies was quite serious, in that after a bite from a rabid animal, the disease was usually lethal, and the illness and death quite horrible. This kind of situation, as well as the long incubation interval between the initial bites and the onset of symptoms, which could be several months, lent itself perfectly to a therapeutic intervention, rather than preventative.

As background, a veterinarian from Lyon, Pierre-Victoire Galtier had reported in 1879 that rabies could be transmitted from dogs to rabbits. Galtier also suggested that the long incubation period of rabies suggested that a therapeutic remedy might be applied after infection, but before the symptoms became manifest (Geison, 1995). One other important observation that Pasteur and Roux had established in their studies on chicken cholera and anthrax was that the serial passage of a microbe through the same or another animal species could alter its pathogenicity, either increasing or decreasing its virulence (Pasteur et al., 1881b). Actually, this phenomenon had been utilized in creating the vaccinia virus throughout the nineteenth century, such that the history of the cowpox virus, horsepox virus, smallpox virus, and vaccinia virus became quite convoluted (Smith, 2011).
In this regard the difference between a virus, which must replicate in cells, vs. bacteria, which usually replicate outside of living cells is important, for obviously Pasteur could not have cultivated the rabies virus in vitro, it being a true virus instead of a bacterium. Therefore, his atmosphere-attenuation method could not be used to make a vaccine for rabies. Accordingly, he turned to his experience of passaging microbes in vivo, from animal to animal. Dr. Roux found that if he took brain material from a dog that had died of rabies and inoculated it directly onto the surface of the brain of a healthy dog, through a hole drilled into its skull, that the dog thus inoculated through its trephined skull, invariably displayed rabies symptoms within 3 weeks, as compared to the average of more than a month when dogs had been infected from bites of rabid dogs in the community. Thus, this dog-to-dog transfer presumably increased the virulence of the rabies virus. Pasteur immediately assumed that a shortening of the incubation interval happened as a result of a change in the microbe, whereas Koch, who had observed a similar phenomenon, assumed that the serial passage had simply increased the purity of the microbes transferred (Geison, 1995). Obviously, dosage would be important too, but there was no way that the actual number of transferred organisms could be determined at this time.

Subsequently, over the next few years, Pasteur experimented with methods of serial passage of the rabies virus through different species to ascertain whether he could attenuate its virulence. He then reported in May, 1884 that the serial passage of the virus from dogs through monkeys would attenuate it when re-inoculated back into dogs. Subsequently, in the year between this report and July of 1885, when he began treating the boy Joseph Meister who had been badly bitten by a supposedly rabid dog, Pasteur performed many different kinds of experiments on dogs as well as rabbits. Together with Roux a new method evolved in the lab to try to attenuate the rabies virus. Spinal cords taken from rabbits newly dead of rabies were suspended in flasks open to the air that contained potassium hydroxide as a desiccant, which Pasteur introduced to prevent the cords from putrifying. It appeared to Pasteur that each day of desiccation gradually led to an attenuation of virulence, such that after 14 days, if a portion of the dried cord was emulsified and injected into either rabbits or dogs, it had lost its virulence.

In the course of these experiments, Pasteur's concept of the mechanism of immunity underwent another paradigm shift. According to his notebooks, he began to doubt the validity of his biological "exhaustion" theory, at first in the case of rabies, and then more generally (Geison, 1995). According to an unusually explicit theoretical entry into his notebook on the January 29,1885 , he was growing increasingly confident that he had made an "immense discovery" of potentially "great generality"-namely that the living rabies virus produced an inanimate, soluble, chemical "vaccinal substance" which was detrimental to the continued replication of the virus. This is the mechanism that now Pasteur began to believe was responsible for rendering immunity. It is this thought pattern that led him to experiments using serial inoculations going from fresh spinal cords (virulent) to successively dried (attenuated) spinal cords, instead of the other way around to try to generate immunity.

Despite these new theories, Pasteur related to the Academies des Sciences on October 26, 1885 an almost unbelievable story of 
his successful "therapeutic vaccination" of a young boy who had been bitten multiple times by a rabid dog (Pasteur, 1885).

He began his presentation by explaining how he had started experiments in 1882 with the inoculation of rabies virus from the spinal cord of a rabid dog into rabbits by trepanation, placing it under the dura matter covering the brain. After prolonged passage, $>100 \times$, the incubation interval was reduced from $>15$ to $<7$ days, thereby indicating increased virulence to Pasteur.

He went on to state,

The spinal cords of these rabbits are rabid throughout their length with a constancy in their virulence. If taking the greatest care possible to maintain purity one removes from these cords sections a few centimeters in length, and then suspends them in dry air, virulence slowly disappears until it finally disappears.

Here, Pasteur assumed that the virus in the desiccated jars remained alive but had lost its virulence, and thus was attenuated. However, obviously Pasteur had no way to identify the rabies organisms, or to tell whether they were alive or dead.

Having established these facts, here is the method to render a dog refractory (immune) to rabies in a relatively short time. In a series of flasks in which air is maintained in a dry state. . .each day one suspends a thickness of fresh rabbit spinal tissue taken from a rabbit dead of rabies. Each day as well, one inoculates under the skin of a $\operatorname{dog} 1 \mathrm{~mL}$ of sterilized bouillion, in which has dispersed a small fragment of one of these desiccated spinal pieces, beginning with a piece most distant in time from when it was worked upon, in order to be sure that it is not at all virulent. On the following days, one performed the same procedure with less old spinal tissue, separated by an interval of two days, until one reaches the last most virulent spinal tissue, that was placed only for a day or two in the flask. In this manner is the dog rendered immune to rabies. One can inject it with rabid virus under the skin or similarly on the brain surface by trepanation without rabies appearing.

By the application of this method, I had made fifty dogs of all ages refractory to rabies without a single failure, when unexpectedly on the $6^{\text {th }}$ of July last, three persons from Alsace presented themselves to my laboratory. Joseph Meister, 9 years old. . had suffered not less than 14 wounds from a rabid dog two days previously.

As the death of this child appeared inevitable, I decided, not without deep and severe unease, as one can well imagine, to try on Joseph Meister the procedure which had consistently worked in dogs.

Pasteur then describes 13 inoculations given over 10 days to the boy, beginning with spinal cords that had been desiccated for 14 days and progressing to fresh spinal cord material. As of the time of the Academie meeting, Joseph Meister had remained healthy for 3 months and 3 weeks.

Pasteur then went on to speculate as to why his vaccination had worked.

"What interpretation should we give to this new procedure that I have made known to prevent rabies after a bite". . . Many microbes appear to give rise in their cultures to material that have the property to impede their own development. . Could it be that the rabies virus is comprised of two distinct substances, side by side, one which is living and capable of multiplying rapidly in the nervous system, and another, not alive, having the faculty, when in a suitable amount to inhibit the development of the first?

After this presentation, Pasteur gradually withdrew from active experimentation, until his death in 1895 at age 73 .

\section{CONCLUSION}

Pasteur's reports created an explosion of demand by farmers from all over the world for the anthrax vaccine so that they could vaccinate their livestock. Pasteur's quotation of Virgil's "Audentes fortuna juvat (luck comes to the bold)" is particularly apt in this regard. Pasteur was lucky, given his theories as to how vaccination produced immunity, that the famous Pouillyle-Fort trial was designed with two immunizations given 2 weeks apart. We now know that it takes at least 2 weeks for the primary immune response to develop and evolve so that memory cells can respond more rapidly and with greater intensity to the secondary injection of antigen. This same timing was working in Pasteur's favor with his therapeutic regimen for the rabies vaccine, when he started with the least fresh desiccated spinal cord and progressing to the most virulent fresh spinal cord over 2 weeks of injections.

The nature of the anthrax vaccine that Pasteur's laboratory supplied to the many people who requested doses for their animals remains obscure, but was probably the potassium-bichromatetreated vaccine. Parenthetically, it is noteworthy that the vaccine was manufactured commercially by Pasteur's team, in a lab around the corner, yielding a substantial income for the new Pasteur Institute, which was initiated in 1885. Therefore, this is one of the first, if not the first, example of a biotech company, and one that was used to support continued academic research.

The anthrax vaccine that is in use today to immunize atrisk wool mill workers, veterinarians, laboratory workers, livestock handlers, and members of the Armed Service is a cellfree filtrate, so that it is a "subunit vaccine" and consists of the Protective Antigen protein, not attenuated microbes as promoted by Pasteur. The vaccine was developed in the 1950s and 1960s for use in humans and was licensed by the FDA in 1970 (http://www.cdc.gov/mmwr/preview/mmwrhtml/rr4915a1.htm). It has undergone extensive testing in monkeys and has been found to be effective in protecting against pulmonary anthrax after an experimental aerosol challenge.

Accordingly, just as in diphtheria and tetanus, the virulence of anthrax can be prevented by vaccination, not against the whole living microbe as imagined by Pasteur, but against the toxins released by the microbe, when denatured and made into toxoids as demonstrated by von Behring and Kitasato (1890), who first demonstrated that immunization results in a host response by the formation of antitoxin activity in the sera.

As for rabies, after Pasteur's initial report in 1885, donations poured in from all over the world, which went toward the construction of the first building of l'Institut Pasteur, which opened 
in 1888. Pasteur had an apartment in the building, where he spent much of his time until his death. The rabies vaccines, which were produced and sent worldwide initially consisted of desiccated nervous tissue, which was used as the vaccines for $\sim 10$ years until 1895 , when carbolic acid-inactivated nervous tissue-derived vaccines were introduced, followed by phenol-inactivated nervous tissue-derived vaccines in 1915 (McGettigan, 2010). These vaccines were then used for the next 40 years until the mid 1950s when tissue culture-derived inactivated rabies virus was first used for the rabies vaccine, which is still in use today. However, ironically, live, but replication-deficient rabies virus vaccines are in development now, and they provide the hope that single-dose human live rabies vaccines will replace the current inactivated vaccines,

\section{REFERENCES}

Cagniard-latour, C. (1838). Memoire on alcohol fermentation. Ann. Chim. Phys. 68, 206-222.

Geison, G. (1995). The Private Science of Louis Pasteur. Princeton, NJ: Princeton University Press.

Hooke, R. (1665). Micrographia. London: Martyn and Allefrey, Printers to the Royal Society.

Hugo, V. (1862). Les Miserables. Harmondsworth: Penguin Books Ltd.

Koch, R. (1876). Die aetiologie der milzbrand-krankheit, begrundet auf die entwicklungsgeschichte des Bacillus antracis. Beitr. Biol. Pflanz. 2, 277-310.

Lister, J. (1867a). On a new method of treating compound fractures, abscesses, etc. With observations on the conditions of suppuration. Lancet 1, 326, 357, 387, 507.

Lister, J. (1867b). On the antiseptic principle in the practice of surgery. $B r$. Med. J. 2, 246.

McGettigan, J. P. (2010). Experimental rabies vaccines for humans. Expert Rev. Vaccines 9, 1177-1186.
Metchnikoff, E. (1939). The Founders of Modern Medicine: Pasteur, Koch, Lister. Freeport, NY: Books for Libraries Press.

Pasteur, L. (1857). Memoire sur la fermentation appelee lactique. (Extrait par l'auteur). C. R. Acad. Sci. 45, 913-916.

Pasteur, L. (1860). Memoire sur la fermentation alcoolique. Ann. Chim. Phys. 58, 323-426.

Pasteur, L. (1861). Memoirs sur les corpuscles organises qui existent dans l'atmosphere. Examen de la doctrine des generations spontanees. Ann. Sci. Nat. 16, 5-98.

Pasteur, L. (1880). Sur les maladies virulentes, et en particulier sur la maladie appelee vulgairement cholera des poules. C. R. Acad. Sci. 90, 249-248.

Pasteur, L. (1885). Methode pour prevenir la rage apres morsure. C. $R$. Acad. Sci. 101, 765-774.

Pasteur, L., Chamberland, C., and Roux, E. (1881a). Compte rendu sommaire des experiences faites a Pouilly-LeFort, pres de Melun, sur la vaccination charbonneuse. C. R. Acad. Sci. 92, 1378-1383.

with their associated toxicity and complicated repetitive dosing regimens.

In France, one can be an anarchist, a communist or a nihilist, but not an anti-Pastorian. A simple question of science has been made into a question of patriotism.

(Pasteur et la Rage)

[Pasteur] was the most perfect man who has ever entered the kingdom of science.

(The Spectator)

\section{ACKNOWLEDGMENTS}

The author thanks the Belfer Foundation and the Rubin Foundation for their support.

Pasteur, L., Chamberland, C., and Roux, E. (1881b). De l'attenuation des virus et de leur retour a la virulence. C. R. Acad. Sci. 92, 430-435.

Pasteur, L., Joubert, C., and Chamberland, C. (1878). La theorie des germes et ses applications a la medicine et a la chirurgie. C. R. Acad. Sci. Hebd. Seances Acad. Sci. 86, 1037-1043.

Schwann, T. (1837). Preliminary report on experiments concerning alcoholic fermentation and putrefaction. Ann. Phys. 41, 184-193.

Smith, K. (2011). Edward Jenner and the smallpox vaccine. Front. Immunol. 2:21. doi:10.3389/fimmu.2011.00021

Theiler, M., and Smith, H. (1936). The use of yellow fever virus modified by in vitro cultivation for human immunization. J. Exp. Med. 65, 787-800.

von Behring, E. A., and Kitasato, S. (1890). Ueber das zustandekommen der diphtherie-immunaitat und der tetanus-immunitat bei thieren. Dtsch. Med. Wochenschr. 16, 113-114.

Conflict of Interest Statement: The author declares that the research was conducted in the absence of any commercial or financial relationships that could be construed as a potential conflict of interest.

Received: 05 February 2012; paper pending published: 04 March 2012; accepted: 19 March 2012; published online: 10 April 2012.

Citation: Smith KA (2012) Louis Pasteur, the father of immunology? Front. Immun. 3:68. doi: 10.3389/fimmu.2012.00068

This article was submitted to Frontiers in Immunological Memory, a specialty of Frontiers in Immunology.

Copyright (c) 2012 Smith. This is an open-access article distributed under the terms of the Creative Commons Attribution Non Commercial License, which permits non-commercial use, distribution, and reproduction in other forums, provided the original authors and source are credited. 